\title{
Resources for Innovative Development of the Region in the Context of Digital Economy
}

\author{
Serebryakova N.A.* \\ Voronezh State University of Engineering Technology \\ Voronezh, Russia \\ e-mail: nad.serebryakova@mail.ru
}

Solomatina E.D.

Plekhanov Russian University of Economics

Russian Federation

e-mail: soloha73@mail.ru

\author{
Dorokhova N.V. \\ Voronezh State University of Engineering Technology \\ Voronezh, Russia \\ e-mail: nv_dorohova@mail.ru
}

\author{
Salikov Yu.A. \\ Voronezh State University of Engineering Technology \\ Voronezh, Russia \\ e-mail:saural@rambler.ru
}

\author{
Isaenko M.I. \\ Voronezh State University of Engineering Technology \\ Voronezh, Russia \\ e-mail: misaenko90@yandex.ru
}

\author{
Vitruk L.Yu. \\ Voronezh State University of Engineering Technology \\ Voronezh, Russia \\ e-mail: balllet@yandex
}

\begin{abstract}
The article is devoted to the solution of important national economic problem such as looking for options to increase the efficiency of resource support for the innovative development of regional ecosystems in the context of the digital economy. The concept of a regional innovation system has been clarified and approaches to the interpretation of its structure have been highlighted. The exceptional role of human resources for the innovative development of regions in the context of the digitalization of the economy has been justified. The requirements for human resources that are adequate to the process of digitalization of the economy have been identified. The relationship between the effectiveness of innovative development of the region and the features of the functioning of the regional labor market has been indicated. We have proposed a mechanism to improve the effectiveness of interaction among regional labor market regulatory policies with a view to resolving conflicts of interest. This mechanism is a social partnership in which consensus can be found among regional development stakeholders.
\end{abstract}

Keywords - resource support, innovative development, digital economy.

\section{INTRODUCTION}

The improvement of the innovative development of regional ecosystems in the Russian Federation has been a pressing issue for quite some time. It has acquired special significance and content in connection with the development of the digital economy.

The term "digital economy" has become widespread relatively recently, although at the end of the twentieth century, the American scientist N. Negroponte introduced it into scientific circulation. As a key feature of the digital economy, he called the fundamental changes in information transfer technologies: "When information is embodied in atoms, there is a need to deliver it to all kinds of industrial-era vehicles and huge corporations. But when everything goes to bits, the traditional forms are no longer needed» $[1,15]$. The scientific literature to date has not developed a clear and unambiguous approach to the definition of the digital economy. This is despite the fact that the process of digitization has now been extended to all sectors of society and the development of the digital economy has shown a steady positive trend. Thus, according to researchers at the Higher School of Economics, «The ICT sector is one of the fastest growing segments of the Russian economy. For the period 2010-2017 it grew by 17\%, almost double the rate of GDP growth. The sector's share in GDP is $2.7 \%$.» [Higher School of Economics, 2018].

Currently, the digitalization of the economy in our country is receiving increasing attention. In July 2017, the state program "Digital Economy of the Russian Federation" was adopted, the implementation of which will end in 2024. «A key factor in the successful implementation of this program is the achievement of consensus in determining the strategic goals of the socio-economic development model chosen by society, based on a fundamental rethinking of the role, challenges and functions of the state in a digital economy. Additionally, the Russian Federation, as a complex federal state faces another major challenge in this regard: to ensure a balanced nature of the implementation of this program across all 85 subjects. Hence the establishment of one of the key objectives of the gradual digitization of the economy is expanding the geography and accelerating the scientific, technological and innovative development of Russia through the development and implementation of breakthrough technologies and the creation of promising centers of economic growth throughout the country». (Kurochkin A.V., Godunova E.A. Factors of the effectiveness of innovative development of the region in the context of the digital economy) 
The process of digitization of economy has a significant impact on the resources for innovation. This is because information and knowledge are becoming the main resources. This, in turn, brings about adjustments in the management of innovative development at the regional level.

Thus, the purpose of this study is to develop proposals for improving the resource support of innovative activities in the region in the context of digitalization of the economy. In order to achieve the stated goal, it is necessary to solve a number of tasks: to clarify the definition of the concept of «resourcing of innovative development of the region»; to identify the directions of transformation of the composition of resources for innovative development in the context of digital development; suggest the ways of improving resources for innovative regional development.

\section{MATERIALS AND METHODS}

The theoretical and methodological basis of the study is dialectical, historical, abstract logical and other general scientific methods of cognition, as well as systemic, situational and business case approaches, comparative analysis, empirical generalization, index method, hierarchy analysis method, tabular and graphical visualization techniques of statistical and calculated data. The study was based on official data from the Ministry of Economic Development of the Russian Federation, the Federal State Statistics Service, scientific publications on the problem under study, current information on the state and prospects of the digital economy in Russia and its regions, Internet materials.

\section{RESULTS}

The indicators of innovative development of the regional economy largely depend on the effectiveness of the functioning of the regional innovation system. One of the first authors of the theory of a regional innovation system was P. Cooke, who by the regional innovation system understood the many links of the innovation chain from the moment of generation of new knowledge to the moment of its commercialization. As such links, P. Cooke refers to knowledge-producing organizations, enterprises introducing new knowledge into the production process, intermediaries promoting commercialization of innovation, and innovation infrastructure, Financial and regulatory support [14]. In defining the driving forces of innovation at the regional level, P. Cooke emphasizes the role and importance of social and productive processes as a means of generating, disseminating and using new knowledge.

So far, several approaches to defining the definition of «regional innovation system», namely institutional, functional and integrated, have emerged in scientific research. Moreover, the last of the listed approaches seems to be the most adequate to the realities of the modern economy. Agreeing with the position of Bibik S.N., it can be noted that the innovation system of the region is "a complex of interconnected institutional structures that develop, manufacture, implement and commercialize new knowledge and technologies in order to increase the competitiveness of the region as a certain economic space". This system has a complex structure and is characterized by a number of features: (fig. 1)

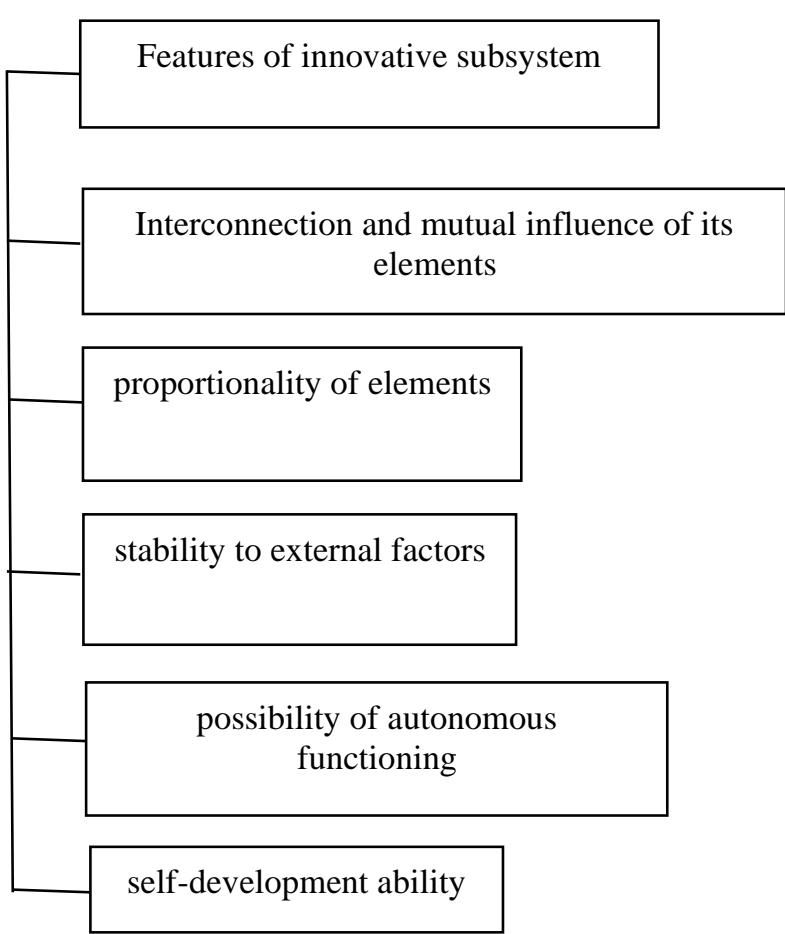

Fig. 1. Features of an innovative subsystem

Summarizing all of the above mentioned aspects, it can be concluded that the innovation system of the region is a system with some ordered and interacting elements oriented towards the production, dissemination and consumption of new knowledge, intended for practical use in the production process. "However, the knowledge created, disseminated and used, does not always circulate in the form of products and services, but can also have a social impact. The internal mechanism of RIS is largely described by the principle of the triple helix of innovation by Henry Etzkowitz and L. Leydesdorff. The concept of a triple spiral of innovation underlies the construction of a regional innovation system, as it reveals the relationship of its main participants: government, business and research. Participants in the regional innovation system interact through production (generation), diffusion and use of new knowledge » [15].

It is necessary to note that in modern environment it is the development of an innovative system that is essential for the digitization of the economy. At the same time, the process of digitization of the economy has significantly altered the resource base for the innovative development of regional ecosystems, further emphasizing the role of human resources in this process. Thus, concurring with S.E. Metelev's position, we note that "the problems of the innovative and socioeconomic development of the region are primarily determined by the region's intellectual resources, which, in the context of the migration of human resources, put at risk the implementation of territorial development strategies. Innovation should therefore be seen not only as a means of increasing the competitiveness of economic agents, but also as an opportunity to improve the population's living conditions through the creation and diffusion of innovations, as well as the improvement of social and economic climate in the 
region» [16]. Thus, in the context of the digitization of regional systems, human resources and their capacity to generate knowledge and developed digital competencies are the basis for the innovative development of regional systems.

The development of human resources depends to a large extent on the efficiency of the labour market in the region, which is determined, inter alia, by the institutional conditions created and modified by the regional labour market policy. The current institutional conditions at the regional level, in our view, are not conducive to the development of human resources and do not motivate the development of digital competences. One of the main reasons for this situation is that the existing organizational conditions do not allow for the full realization of the interests of all subjects of the labor market regulation policy in the region, namely government and administrative bodies, local governments, representatives of employees and representatives of employers, educational organizations, research and development, civil society institutions.

All political actors pursue their own interests in the labour market (fig. 2).

\begin{tabular}{|c|c|c|}
\hline №ף & Subjectsa & Interests \\
\hline 10 & $\begin{array}{l}\text { Authorities and local government- } \\
\text { bodieso }\end{array}$ & 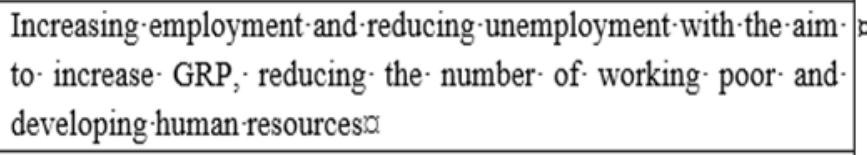 \\
\hline 20 & Union representatives (trade unions) a & 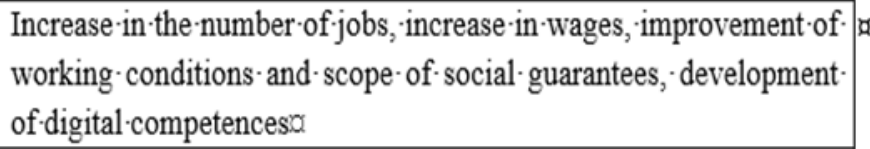 \\
\hline 30 & Employers unions representativeso & $\begin{array}{l}\text { Improving the quality of the labour-force, increasing the supply of - } \\
\text { labour- and, as a consequence, - increasing - competition - among } \\
\text { employeeso }\end{array}$ \\
\hline 40 & $\begin{array}{l}\text { Education, research } \text { and development- } \\
\text { organizations } 0\end{array}$ & $\begin{array}{l}\text { Ensuring the demand for educational-services-(vocational training, } \\
\text { retraining and advanced training of all- categories - of citizens), } \\
\text { improving the quality of the workforcex }\end{array}$ \\
\hline 50 & Civil-society institutions 0 & $\begin{array}{l}\text { Ensuring social justice and protecting the interests of socially } \\
\text { vulnerable-citizenso }\end{array}$ \\
\hline
\end{tabular}

Fig. 2. System of interests of labour market policy actors in the region

Thus, all actors of labour market policy in the region are interested in the formation and effective functioning of the labour market and are ready to participate in the formulation and implementation of this policy. Since their own interests often lie in different ways, they exhibit opportunistic behavior. Consequently, the improvement of the organizational conditions for the formation and development of the labour market in the region should aim at the leveling-off of the opportunistic behavior of policy-makers with a view to reconciling their divergent interests and achieving regulatory policy objectives in the labour market, the regional economic system with human resources of the required quality [17].

In our view, reconciling the divergent interests of labour market policy actors is possible only within the framework of a social partnership system.

It should be noted that the institution of social partnership has important social and economic functions. The social functions of this institution are to organize, regulate and streamline the social life and behavior of people in the social and labour sphere. Economic functions can be understood as the ability of social partnership to regulate the behavior of labour market actors [16].
To give effect to the interests of the labour market policy subjects of a region in the framework of social partnership is possible in the format of public discussion of plans, forecasts, strategies and indicative planning (fig.3).

To sum up, the institutional environment is one of the fastest-changing and most flexible phenomena, but at present it does not create the conditions for the development of the human potential of the region and do not motivate the development of digital competencies. The main reason for this situation is the divergent interests of all the stakeholders in the regional labour market. The author justifies the need to use social partnership to reconcile the interests of the subjects of labour market policy with a view to their full realization and the achievement of strategic goals; as well as providing the region's innovative system with human resources of the required quality.

\section{CONCLUSION}

Innovative development of the regional economic system is the basis for increasing its competitiveness. The innovative development path gains special significance in the context of the digitalization of the economy, since on the one hand it acts as the basis for the development of the digital economy, on the 
other hand, digitalization acts as a catalyst for innovative processes at the regional level. At the same time, the problem of resource support for innovative development in terms of increasing the role of human resources in this process is being mainstreamed. Human resources with the ability to generate knowledge and information, acting as holders of digital competencies, ensure the growth of innovative activity in the region. At the same time, the opportunities for realizing the available human resources knowledge and skills are directly dependent on the effective functioning of the regional labor market. Its regulation through a social partnership mechanism allows for the reconciliation of the diverse interests of all entities in order to ensure the innovative development of the regional economic system.

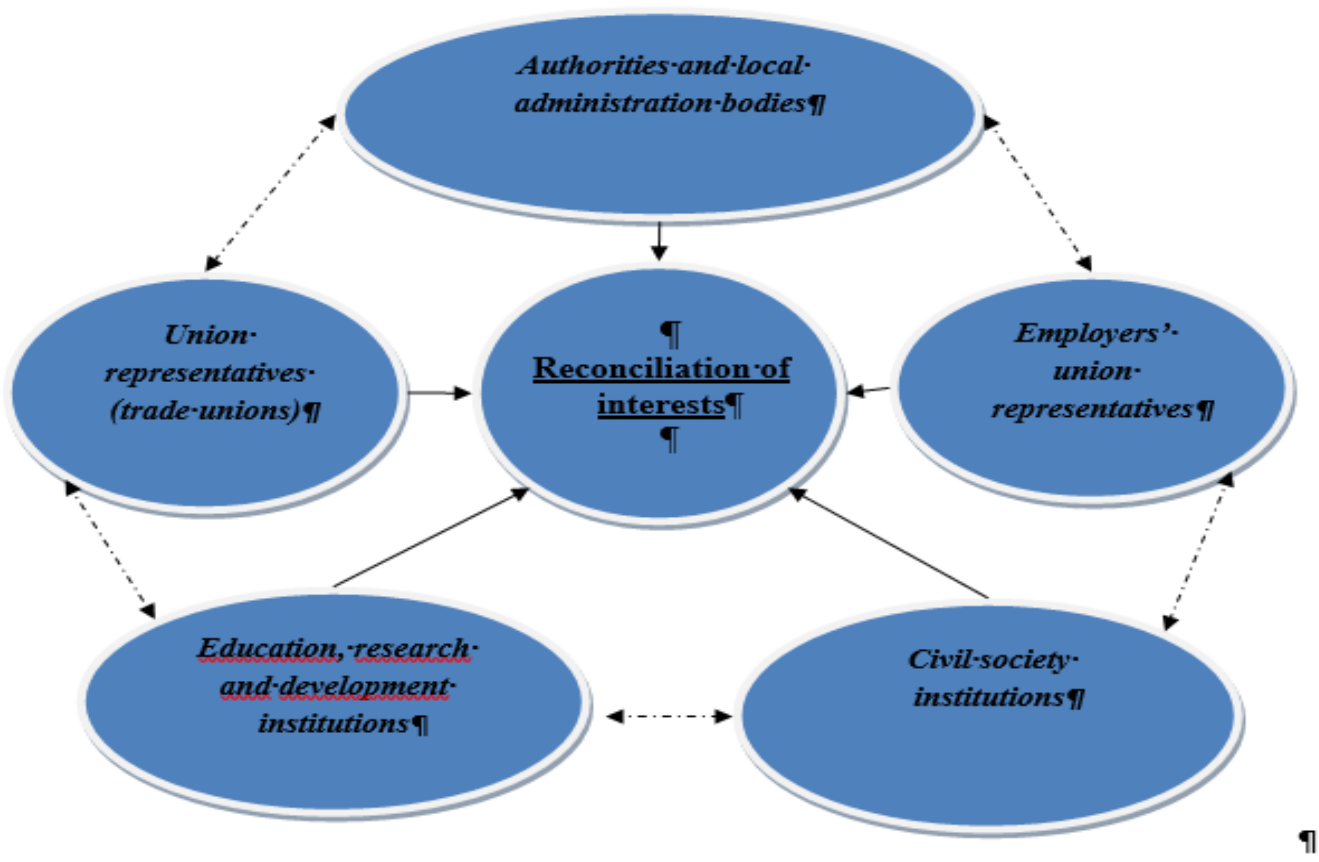

Fig. 3. Reconciling the interests of labour market policy actors through social partnerships

\section{References}

[1] T. Adams, Rediscovering Thomas Adams: rural planning and development, ed. by W. Caldwell. Vancouver: UBC Press, 2011, XXIV, $400 \mathrm{p}$.

[2] P. Cooke, M.G. Uranga, G. Etxebarria, Regional systems of innovation: an evolutionary perspective, In: Environment and Planning, 1998, pp. 63-84.

[3] F. Cruz-Jesus, T. Oliveira, F. Bacao, Z. Irani, Assessing the pattern between economic and digital development of countries. DOI: 10.1007/s10796-016-9634-1

[4] A.G. Granberg, Fundamentals of regional economy: the textbook for higher education institutions, 3rd prod. Moscow: GU HSE, 2003, 495 p.

[5] E.W. Hill, J.F. Brennan, "A Methodology for identifying the drivers of industrial clusters: the foundation of regional competitive advantage", Econ. Development Quarterly, vol. 14, no. 1, pp. 67-96, 2000.

[6] J. Hinderink, M. Titus, "Small towns and regional development: major findings and policy implications from comparative research", Urban Studies, vol. 39, no. 3, p. 391, 2002.

[7] J. Humphrey, Opportunities for SMEs in developing countries to upgrade in a global economy. Geneva: Int. Labour Office, 2003, 38 p

[8] L. Hurwicz, K.J. Arrow, S. Karlin, P. Suppes et al., Optimality and informational efficiency in resource allocation processes, In: Mathematical Methods in the Social Sciences. Stanford: Stanford Univer. Press, 1960.

[9] D. Meadows, D. Meadows, J. Randers, The limits to growth: the 20-year update. Chelsea Green Publ., 2004, 338 p.

[10] L. Pinter, P. Hard, P. Bartelmus, Indicators of sustainable development: proposal for a way forward. New York : IISD, 2005, $42 \mathrm{p}$.
[11] Porter, M.E. The Economic Performance of Regions, Reg. Studies, vol. 37, no. $6 \& 7,578$ p., 2003. Retrieved from: http://www.isc.hbs.edu/ pdf/Porter2003.pdf

[12] Synopsis of policy options for creating a supportive environment for innovative development. Economic commission for Europe committee on economic cooperation and integration. Geneva, 2008. Retrieved from:: http://www.unece.org/fileadmin/DAM/ceci/ documents/2008/ session3/ECE_CECI_2008_3.pdf

[13] V. Boitier, "The role of labor market structure in urban sprawl Regional Science and Urban Economics", vol. 73, pp. 83-98, 2018. Retrieved from: http://www.journals.elsevier.com/regional-science-and-urbaneconomics/ DOI: 10.1016/j.regsciurbeco

[14] P. Cooke, M.G. Uranga, G. Etxebarria, Regional systems of innovation: an evolutionary perspective, In: Environment and Planning, 1998, pp. 63-84.

[15] P.A. Sukhanova, Model of a regional innovation system: domestic and foreign approaches to the study of regional innovation systems. Retrieved from: https://docviewer.yandex.ru/view/121332298/

[16] C.E. Metelev, "Intellectual resources for the innovative and socioeconomic development of the region: the institutional dimension", Mordern Sci. Achievements, vol. 2, no. 4, pp. 17-232016.

[17] N.A. Serebryakova, Y.A. Salikov, N.V. Dorokhova, M.I. Isaenko, N.V. Grishchenko, "Methodological approaches to formation of corporate entities: evidence from food industry", Int. J. of Econ. Perspect., vol. 11, no. 3, pp. 405-412, 2017.

[18] N.A. Serebryakova, N.V. Dorokhova, M.I. Isaenko, Formation of the System of Clustering as a Means of Perspective Development of Innovational Infrastructure of Region, In: Integration and Clustering for Sustainable Economic Growth. Springer, Cham, 2017, pp. 133-142. 